\title{
Analysis of the Influence of Financial Innovation on the Statistics of Social Financing Scale
}

\author{
Qionglin Li \\ Basic Department of College of Technology \& Engineering, Yangtze University; Jinzhou Hubei \\ 434000, China
}

Keywords: financial innovation; social financing scale statistics; impact Analysis.

\begin{abstract}
The direct reflection of the financial industry on the real economy is in the social financing model. In recent years, the financial industry has developed rapidly and the social financing model has been gradually optimized and improved, which has promoted the integration of Chinese financial industry and modern development. So this paper made the discussion and exploration with the influence of financial innovation on the statistic of social financing scale, regarding the real economy of financial industry as the research object.
\end{abstract}

\section{Introduction}

Affected by the macro adjustment of Chinese government, the financing scale of financial industry has gotten increasing growth. For example, the Government Working Report published by Premier Li Keqiang in 2016 regards 13\% as the goal of balance increasing of social financing scale for the first time and looks social financing scale as the important content of Chinese macro adjustment index. Financial industry has been affected to some degree under the pushing of modern innovation development concept, making the statistics of social financing scale gradually develop towards the complete and accurate direction. Seeing from the analysis result of social financing scale index from all walks of life.

\section{Concept and Classification of Social Financing Scale Statistics}

"Social financing scale" is another new concept in the modern economic and social development. Viewing from the perspective of the entire society fund supply, social financing scale can directly express the phenomenon of the financial system giving supply to the real economy. Therefore, the "social financing scale" is the total amount of a real economy obtaining funds from the financial system within a certain period of time, which is a new concept in the financial system and has a high degree of integrity, unity, and completeness. From the perspective of institutions, financial institutions of social financing scale mainly refer to banks, security institutions, and insurance companies; from the perspective of market, the financial markets mainly refer to the stock market, bond market, credit market, insurance market and intermediary business market.

At this stage, Chinese social financing scale can be divided into four types of business and ten sub-businesses. First, the type of business within the financial institution which mainly refer to various loan transactions in Renminbi and foreign currencies; Second, out-of-balance-sheet operations of financial institutions, mainly involving the entrusted loan business, trust loan business and undiscounted bank acceptance draft business; third, the type of direct financing business, which mainly refers to the enterprise bond financing business and domestic stock financing business of non-financial enterprise; fourth, the business types of other projects, mainly involving compensation business of insurance company, loan business of the loan company and investment real estate business. 


\section{Design Principles of Social Financing Scale Statistics System}

The construction of the statistical index system for the social financing scale is to integrate complementary and relevant statistical indicators so that different social financing scale indicators can be integrated and interlinked to form an independent organism. Therefore, the statistical system of social financing scale is of Openness, level and structure. On the basis of social financing scale statistical system, the application of advanced ideology and excellent policy schedules to the design work of social financing scale statistical system can achieve the innovation and reform with financial products. Therefore, it should strictly obey the principles of purpose, substance and market during the design and innovation process so as to make the system scientific, essential, feasible and cutting-edge.

\subsection{Design Principle of Purpose}

Design principle of purpose is the development product of "people oriented", which regards certain regional purpose and performance purpose as the design standard of financial products. It launches the corresponding financing activities within certain statistical regions and financial innovation can be included into the statistical region of financial scale through looking domestic, overseas and individual institutions as the financing methods of capital products. Thus, financial innovation has some direction in the investment of social financing scale statistics, positively catering to various demands of financial markets and constantly expanding the running methods of financial market.

\subsection{Design Principle of Substance}

The design principle of substance means that, on the development basis of financial system, financial products are distributed into the real economy such as industry, agriculture, construction, industry and commerce, transportation and infrastructure under the role of these real economies. It can mainly accelerate the circle rate of financial products and gradually expands the running range of social financing scale statistics to make the statistical system have the comprehensibility, adaptability and development, strengthen the funds immersion among various industries, enhance the accuracy, system and integration of statistical results and avoid the missing of statistical work or repeating phenomena.

\subsection{Design Principle of Market}

The market-oriented design is far from the application of the social financing scale statistical system, which can realize the transformation from the real economy to the financial system, enable financial products to enhance their own value in the market operation, create circulation value, and give full play to the creativity and innovation of market circulation channels. Therefore, its design should strictly follow the principle of market to coordinate the social financing scale statistics with the development of modern society, follow with the pace of times development, focus on the perfect combination of the theory and practice and constantly optimize and integrate the social financing scale statistics system to keep pace with the era.

\section{Various Methods to Acquire Funds in the Financial System}

Through the analysis of the financing channels used by Chinese real economy to obtain funds from the financial system and statistical framework of social financing scales in Chinese modern society, we can see that part of financial services are still not included in the social financing scale statistical system. The related research shows that some financial services have not been included in the social financing scale statistical system, which is mainly affected by the design and formulation process of the social financing scale statistical system in 2011. That is, the government workers lack the importance with those financial business having smaller factors when formulating social financing scale statistics system in 2011, not including those finical business with minor factors to social financing scale statistics system.

Along with the gradual deepening of innovation concept, financial market has gotten certain degree of optimization and reform, and the ignoring factors in the original social financing scale 
statistical system have made a deep influence in the modern financial development environment, badly affecting the structure and total amount of social financing scale. Viewing from the business relationship among current Chinese financial institutions, various businesses appear the development tendency of cross-institutions, industries and markets, making financial products having strong crossing and social financing scale gradually expanding. From the perspective of the operation condition of financial products in the market, those ones with crossing float to the real economy market by means of the direct or indirect channels. Bottom capitals in the investment products are included into the social financing scale statistics system. In order to avoid the repeated and missing statistics, the social financing scale statistical system needs further research and analysis.

\section{Products not Included into the Social Financing Scale Statistics}

\subsection{Emerging Stock Market}

In the new stock market, the New Third Board financing business and the fourth board market financing business have not yet been included in the social financing scale statistics, as the innovative financial products of social financing products, which have emerged in recent years. For example, "New Third Board financing business". The national share transfer system for small and medium-sized enterprises is called the "New Third Board" and this system was registered and established in late 2012 and was officially launched in early 2013. Since the end of 2013, the "New Third Board" have been piloted from high-tech parks in four cities, and the "New Third Board" business has been constantly promoted throughout the country. The "New Third Board" is a financial product approved by the State Council of China, which is a nationwide securities exchange, strictly in accordance with Chinese financial legislation, and it can provide the needed service for the development of small and medium-sized enterprises nationwide and capital operation. With the continuous development of modern market economy and after three-year development, the New Third Board already has a certain scale of operating market. Relevant statistics show that by the end of 2016, there are more than 10,000 companies with "New Third Board" listed with a total market value of more than 4 trillion yuan and a total stock of over 585 billion shares. Affected by factors such as the scale and quality of operations of listed companies, the market operation trend of the "New Third Board" is not optimistic. The new Third Board industry has welcomed new development since the status and mechanism of the New Third Board in the development of the market have been stipulated in 2016. It can be seen that the inclusion of the New Third Board in the statistics of social financing scale is an inevitable requirement of financial innovation.

\subsection{New Financing Tools}

In the new financing instruments, asset securitization, share mortgage of listed company and financial leasing are new financing channels in the development of modern society. At present, there is no financing product that has been included in the social financing scale statistics. For instance, securitization of credit assets in banks is a basic asset that uses funds from the real economy market as credit assets. When the underlying assets are partially or completely out of the table and the bank removes the part of the underlying assets that has already been issued from various types of loans. Failure to fully account for this part will reduce the assessment level of the real economy. Therefore, it is necessary to include asset securitization in banking institutions into the scope of social financing scale statistics; in the securitization of assets generated in non-banking institutions, the design entities of RMB loans and foreign currency loans are all involved in the general government. Therefore, it is impossible to split the asset securitization of enterprises and institutions, and it is necessary to ensure the uniformity and coordination of asset securitization.

In the bond financing channels, the listed company stocks pledge is a common form. Instead of obtaining funds through the purchase of listed securities, the issue of insufficient liquidity in the company can be avoided. Judging from the stock pledge of listed companies used in Chinese market, it can be divided into two forms: the one is the form of internal pledge, and the other is the form of off-site pledge. Both types of pledges have not been included in the social financing scale statistics, resulting in a fragmented state of social financing scale statistics. 


\section{Financial Innovation in the Social Financing Scale Statistics}

\subsection{The Perspective of Statistical Definition Matching}

From the perspective of statistical definition matching, firstly, in terms of the emerging stock market, the New Third Board market and the main board market occupy the same legal status in the market application, both of which belong to the national securities trading market; the fourth board market is one regional equity investment site that have been submitted to the State Council since the securities and futures commission, which can regulate the fourth board market. Second, as far as new types of financing instruments are concerned, the legal definitions, accounting standards, business principles, and taxation policies of financial leasing companies have rather strong consistency with the ones of financial leasing companies. The operating number of financial leasing companies in the market is 108.75 times the number of financial leasing companies, and the operating scale of financial leasing companies in the market is 1.57 times the size of financial leasing companies. As financing leasing companies and financial leasing companies are not responsible for the same regulatory department, and financing leasing companies are divided into leasing and business service industries in the statistics of social financing, and financial leasing companies are divided into financial industries.

\subsection{The Perspective of Statistical Data Feasibility}

Social financing scale statistics is analyzed from the perspective of statistical data feasibility. Whether social financing scale statistics incorporates financial innovation products in its own development and operation is due to the integrity and timeliness of data collection and data statistics work of financial innovation product. It can be seen that the development of the New Third Board financial products in the market is relatively mature, and the availability of various types of data is relatively high; while the financing products in the fourth board market are scattered in the market, and the transparency of data information is relatively low, lacking certain feasibility; the development of asset securitization products and stock pledged products listed companies in the market are relatively mature, and all types of data have high feasibility; the CBRC data generated in financing leasing products are easily available, but business data are consistently in the missing state; there exists the missing data in the industry investment fund products, which can only be investigated through private organizations; the pawn financing products show missing data; the use of banking crossing financial products is in statistical methods, and statistical principles are not uniform with statistical classification. the main indicators and statistical systems lack completeness and comprehensiveness; the ones of crossing products of non-bank financial institutions lack completeness and comprehensiveness. It can be seen that different financial innovations have impacts with different degrees on the social financing scale statistics, and we should actively integrate financial innovation products into the social financing scale statistical system.

\section{Conclusion}

In conclusion, social financing scale is the total amount of funds obtained by the real economy from the financial system during a certain period of time. The article has started with the significance and concept of social financing scale statistics, comprehensively analyzing various channels of obtaining funds in the financial system and looking the financial innovation as the research background to conduct real-time analysis on financing products not included in the social financing scale statistics, which can help to understand the application feasibility and necessity of financial innovation strategy in the social financing scale and provide theoretical reference for the statistics of social financing scale in Chinese later period.

\section{References}

[1]. Sa Zhang. Analysis of the Influence of Financial Innovation on the Statistics of Social Financing Scale[J]. Financial Aspect, 2017(06):70-77. 
[2]. Xiaohua Du. Research on the Effect of Chinese Social Financing on Economic Growth[D]. Jilin University, 2016.

[3]. Yongdong Chai. Research on the Impact of Social Financing Scale and Methods on Economic Growth[D]. Central University of Finance and Economics 2015.

[4]. Liping Jiang. Study on the Social Financing Scale and the Monetary Policy Transmission Based on VAR Model[D]. Hunan University,2015.

[5]. Mingkai Cui. Study on the Reform of Chinese Currency and Credit Statistics[D]. Southwestern University of Finance and Economics,2013.

[6]. Chongqing Li. Research on the Statistical Indicator System of Local Social Financing Scale[D]. Shaanxi Normal University,2013. 